\title{
Prompt improvement of a pressure ulcer by the administration of high viscosity semi-solid nutrition via a nasogastric tube in a man with tuberculosis: a case report
}

Tamaki Nakayama, Seiji Hayashi", Kyoichi Okishio, Tomoko Tomishiro, Kaori Hosogai, Yuki Ootsu, Yasushi Morioka, Kazuyoshi Hatsuda, Eriko Naito, Mitsunori Sakatani

\begin{abstract}
Introduction: Semi-solid nutrition with high viscosity has the advantage of reducing gastroesophageal reflux and diarrhea and shortens the duration of administration compared with liquid nutrition. This is the first report describing the administration of semi-solid nutrition with high viscosity via a nasogastric tube, which achieved a remarkable improvement in the patient's nutritional state.

Case presentation: A 67-year-old man (mongoloid race, Japanese) with tuberculosis, a pressure ulcer and malnutrition was admitted to our hospital. He also had right hemiplegia, dysphagia and aphasia as sequelae of a cerebral hemorrhage. Before his admission, he had been treated at another hospital with $600 \mathrm{kcal} /$ day of liquid nutrition via a nasogastric tube, which was insufficient and induced severe malnutrition. After he was admitted to our hospital, we increased the quantity of his liquid nutrition without success because of complications, specifically diarrhea and gastroesophageal reflux. As it was difficult to confirm whether or not he would accept gastrostomy feeding, we administered semi-solid nutrition with high viscosity $(20,000 \mathrm{mPa} \times \mathrm{s})$ via a large-bore nasogastric tube (18 French). Soon after he was started on semi-solid nutrition, his pressure ulcer and malnutrition improved without diarrhea or complications accompanying the large-bore nasogastric tube.
\end{abstract}

Conclusion: When patients have problems with liquid nutrition, such as diarrhea or gastroesophageal reflux, semisolid nutrition via a nasogastric tube is a useful method of achieving improvements in nutritional state in a short period of time.

\section{Introduction}

Enteral nutrition has surpassed parenteral nutrition in terms of safety and physiological benefits $[1,2]$. For a patient who has problems swallowing but has an intact intestinal tract, enteral nutrition is primarily recommended [1]. Semi-solid enteral nutrition has the advantage of lowering the risk of diarrhea and esophageal reflux [3]. Here we report a case in which malnutrition, diarrhea and a pressure ulcer were improved by high viscosity semi-solid nutrition via a large-bore nasogastric tube.

\footnotetext{
* Correspondence: shayashi@kch.hosp.go.jp

National Hospital Organization Kinki-Chuo Chest Medical Center, NagasoneCho, Kita-Ku, Sakai-City, Osaka, 591-8555, Japan
}

\section{Case presentation}

A 67-year-old man (mongoloid race, Japanese) was admitted to our hospital because of a 3-day history of fever. Acid-fast bacilli was found to be smear-positive in his sputum, and a chest radiograph and computed tomography examinations showed parenchymal opacities with scattered fine nodules in his right apical region. $\mathrm{He}$ was diagnosed with pulmonary tuberculosis, so he was started on anti-tuberculosis therapy with isoniazid, rifampicin, ethambutol, and pyrazinamide on the first day that he was hospitalized. He had developed a cerebral hemorrhage 18 months before this hospitalization, and he had right hemiplegia, dysphagia, and aphasia as sequelae. He had been receiving $600 \mathrm{kcal} /$ day of liquid 
nutrition via a nasogastric tube for 6 months before the current hospitalization.

On admission to our hospital, he had a $16.5 \mathrm{~cm} \times 15.5$ $\mathrm{cm}$, grade IV [4] pressure ulcer in the sacral region, from which Escherichia coli and methicillin-resistant Staphylococcus were detected (Figure 1, panel A). His albumin count was $2.2 \mathrm{~g} / \mathrm{dL}$, hemoglobin was $11.1 \mathrm{~g} / \mathrm{dL}$, C-reactive protein was $12.0 \mathrm{mg} / \mathrm{dL}$ (Figure 2) and his body temperature was $38^{\circ} \mathrm{C}$. A liquid nutrition of 200 kcal was administered for 60 minutes, 3 times a day, and this regimen was continued for 2 weeks. In order to improve his state of nutrition and to reduce weightbearing on the sacral region, 1,200 kcal/day of liquid nutrition was administered for a shorter time. This, however, induced watery diarrhea and gastroesophageal reflux. His general condition and malnutrition (low serum albumin) suggested that he would have a poor prognosis if a gastrostomy was performed [5]. It was difficult to confirm whether or not he would accept gastrostomy feeding, so nasogastric tube feeding was continued. As for the preparation, we selected semisolid nutrition with higher viscosity $(20,000 \mathrm{mPa} \times \mathrm{s})$. In order to achieve the administration in a certain short period of time, a nasogastric tube of 18 French was inserted.

As the patient was febrile and bedridden, his total energy expenditure was assessed as 1,708 kcal/day by the Harris-Benedict equation [6] (presumed height 162 $\mathrm{cm}$, presumed body weight $45 \mathrm{~kg}$, ideal body weight $57.7 \mathrm{~kg}$, activity factor $=1.1$, stress factor $=1.5$ ). Considering that his caloric prescription up to that time had been $600 \mathrm{kcal} /$ day and he had diarrhea, we first tried $1,200 \mathrm{kcal} /$ day.

On day 21 in hospital, a semi-solid enteral product of $400 \mathrm{kcal}_{2} 267 \mathrm{~g}$ (PG Soft ${ }^{\mathrm{Tm}}$, Terumo, Tokyo, Japan) was administered for 15 minutes 3 times a day, which was then followed by $250 \mathrm{~mL}$ of semi-solidified water (PG Water $^{\mathrm{ru}}$, Terumo, Tokyo, Japan) and dietary fiber. After starting the semi-solid enteral product, he experienced no diarrhea or esophageal reflux. On day 22, a debridement of the sacral pressure ulcer was conducted. Four weeks later, an improvement was observed in his albumin, hemoglobin, and C-reactive protein levels (Figure 2). His pressure ulcer was then $8.0 \mathrm{~cm} \times 5.0 \mathrm{~cm}$ (Figure 1 , panel D).

No complication of the esophagus, paranasal sinus, or nose wings accompanying insertion of the nasogastric tube was observed. Compliance of the large-bore nasogastric tube was favorable, and he did not try to remove the tube himself. With continuous maintenance of the tube, no obstruction was observed. Administration of anti-tuberculosis drugs was continued via the nasogastric tube without any adverse effects, and tubercle bacillus was not detected in his sputa. After 3.5 months, he
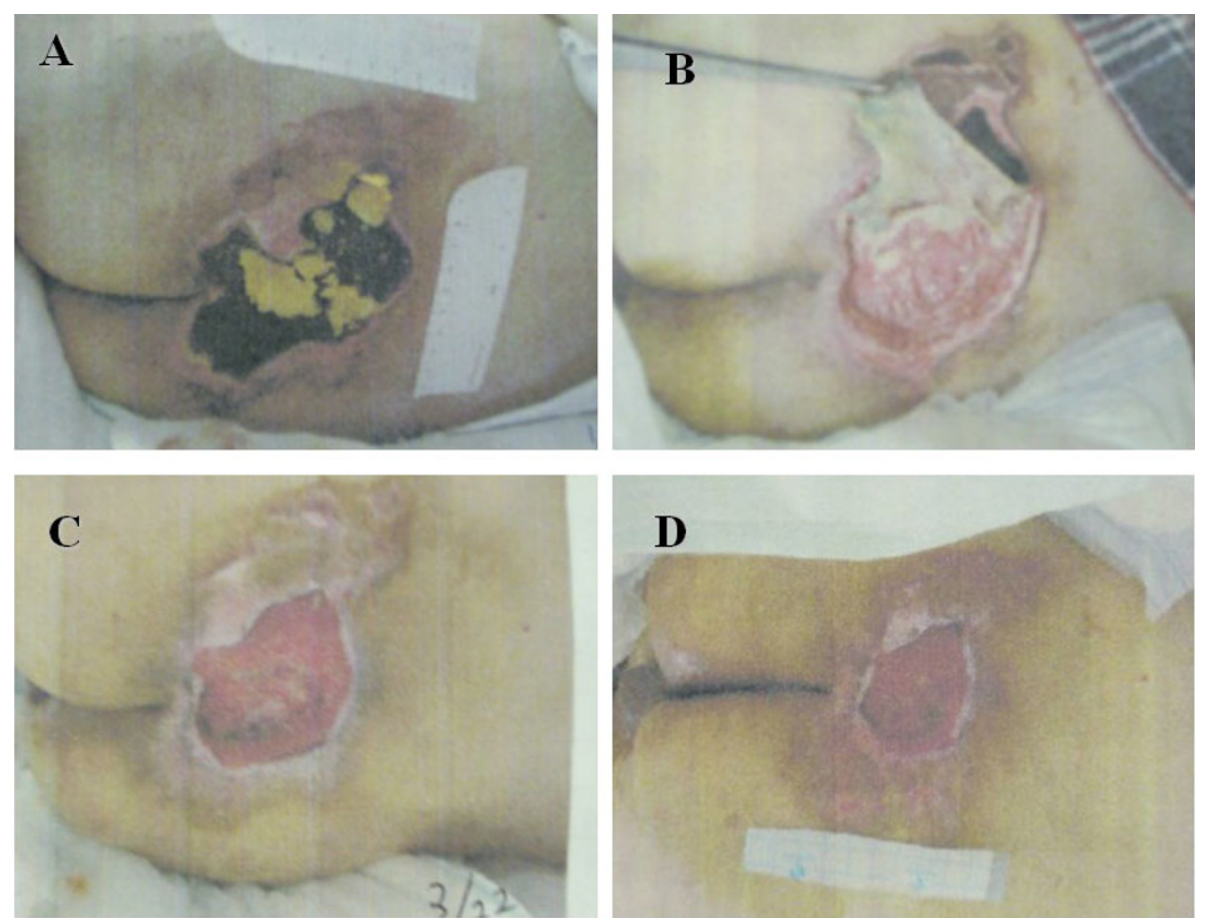

Figure 1 Chronological change of pressure ulcer. (A) Day 0 . The patient had a $16.5 \mathrm{~cm} \times 15.5 \mathrm{~cm}$, grade IV pressure ulcer in the sacral region. (B) Day 22. Debridement was conducted. (C) Day 66. The pressure ulcer had shrunk along with an improvement in the patient's state of nutrition. (D) Day 93. The size of the pressure ulcer was $8.0 \mathrm{~cm} \times 5.0 \mathrm{~cm}$. 


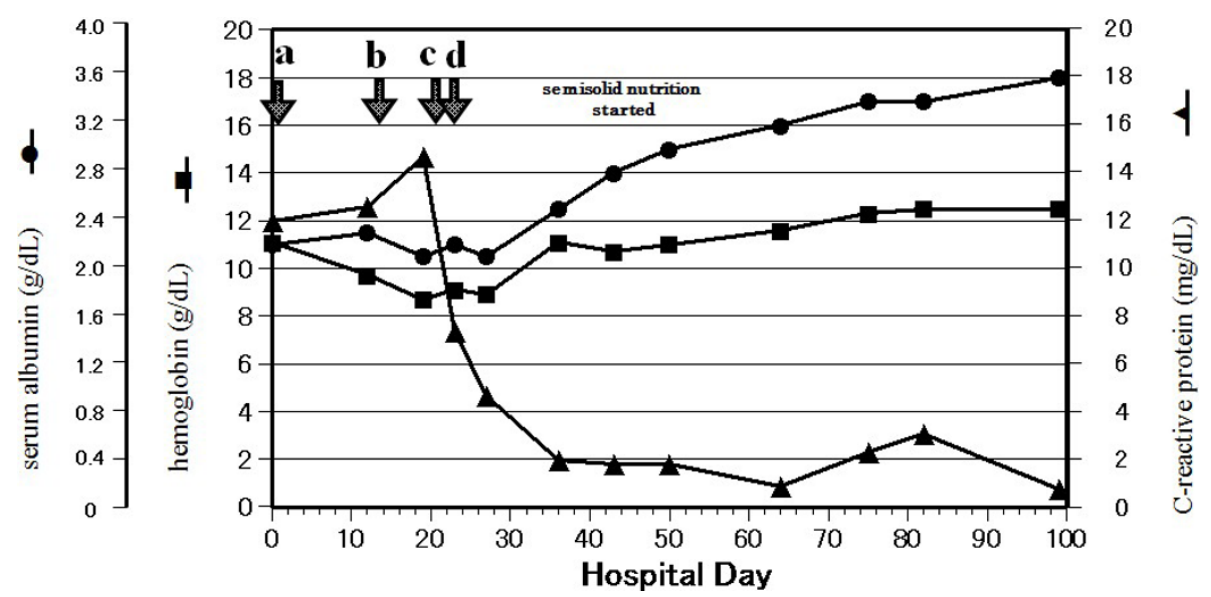

Figure 2 Chronological change of hemoglobin concentration (square), serum albumin concentration (circle) and C-reactive protein titer (triangle). Anti-tuberculosis drugs were started on the first day of admission (arrow a). Liquid nutrition was increased to 1,200 kcal/day on the $14^{\text {th }}$ day of admission (arrow b). Semi-solid nutrition of 1,200 kcal/day was started on the $21^{\text {st }}$ day of admission (arrow c). Debridement of the sacral pressure ulcer was conducted on the $22^{\text {nd }}$ day of admission (arrow d).

was transferred to another facility for further recuperation.

\section{Discussion}

Our case report showed that nutrition improvement and curative effects were obtained by nutrition with a higher viscosity of about $20,000 \mathrm{mPa} \times \mathrm{s}$. In recent years, the advantages of semi-solid nutrition over liquid nutrition have been reported [3]. Liquid nutrition may not be the best choice when it is needed to shorten the administration time and at the same time provide a sufficient amount of calories. A small-bore nasogastric tube is thus recommended from a viewpoint of compliance. However, in this case, liquid nutrition was not appropriate, and so we had no choice but to use a large-bore nasogastric tube.

Due to its higher viscosity, semi-solid nutrition has several advantages. One advantage is the reduction of gastroesophageal reflux with the resultant prevention of aspiration pneumonia [3]. The rate of proximal stomach emptying contributes to the number of reflux episodes per hour [7]. Nutrition with higher viscosity promotes the passage of gastric content to the intestinal tract, which shortens the gastric retention time $[3,8]$. Another advantage is the prevention or improvement of diarrhea. We used semi-solid nutrition for patients with intractable diarrhea who had been administered with liquid nutrition. Improvement of diarrhea was observed in 9 out of 14 , or $64.2 \%$ of patients (unpublished data). The third advantage is that semi-solid nutrition can shorten the duration of administration. The bolus administration of liquid nutrition induces gastroesophageal reflux. Hence, in order to prevent the reflux, continuous administration is required [9]. The manufacturer of the nutrition we used for this patient recommends that the administration of the semi-solid nutrition be done in 15 minutes. Administration should be carried out in a sitting position to minimize gastroesophageal reflux, but this position may impose load to any pressure ulcer at the sacral region.

In order to administer semi-solid nutrition in a short time, we changed the size of our patient's nasogastric tube from small-bore to 18 French, and the pressure ulcer that had existed for a long time disappeared in 3 months. As for amelioration of the pressure ulcer, the favorable effects of debridement and the antibacterial effect of anti-tuberculosis drugs must be taken into consideration. However, it is established that nutrition improvement is indispensable for the amelioration of a pressure ulcer $[10,11]$. Hence, we believe that shortening the administration time of nutrition largely contributed to the improvement of our patient's pressure ulcer.

It is not recommended to administer semi-solid nutrition through a thinner tube with high pressure because the liquid spouting from the tip may injure the gastric mucosa. When semi-solid nutrition is given via a nasogastric tube, there is a risk for tube obstruction, but we avoided this by using a large-bore tube.

\section{Conclusions}

When patients have problems with liquid nutrition, such as diarrhea or gastroesophageal reflux, semi-solid nutrition via a nasogastric tube is a useful method for improving nutrition in a short period of time.

\section{Consent}

Written informed consent was obtained from the patient for publication of this case report and any 
accompanying images. A copy of the written consent is available for review by the Editor-in-Chief of this journal.

\section{Acknowledgements}

This study was supported by a grant-in-aid from the Osaka Tuberculosis Foundation. The authors are grateful to Ms. Reiko Hayashi for her linguistic help.

\section{Authors' contributions}

$\mathrm{TN}, \mathrm{KH}, \mathrm{YO}$ and $\mathrm{YM}$ performed the assessment of the nutrition state and designed the nutrition treatment plan of the patient. SH supervised the nutrition treatment plan, wrote the manuscript, and reviewed the international literature. $\mathrm{KO}, \mathrm{TT}$ and $\mathrm{EN}$ treated the patient's tuberculosis and pressure ulcer. $\mathrm{KH}$ participated in the assessment of the patient's clinical data. MS supervised the treatment of tuberculosis and revised the manuscript for important intellectual content. All authors read and approved the final manuscript.

\section{Competing interests}

The authors declare that they have no competing interests.

Received: 22 November 2008

Accepted: 27 January 2010 Published: 27 January 2010

\section{References}

1. Kochevar M, Guenter P, Holcombe B, Malone A, Mirtallo J: ASPEN statement on parenteral nutrition standardization. JPEN J Parenter Enteral Nutr 2007, 31(5):441-448.

2. Levine GM, Deren JJ, Steiger E, Zinno R: Role of oral intake in maintenance of gut mass and disaccharide activity. Gastroenterol 1974, 67(5):975-982.

3. Kanie J, Suzuki Y, Iguchi A, Akatsu H, Yamamoto T, Shimokata H: Prevention of gastroesophageal reflux using an application of half-solid nutrients in patients with percutaneous endoscopic gastrostomy feeding. J Am Geriatr Soc 2004, 52(3):466-467.

4. Pressure ulcer stages. http://www.npuap.org/pr2.htm

5. Lang A, Bardan E, Chowers Y, Sakhnini E, Fidder HH, Bar-Meir S, Avidan B: Risk factors for mortality in patients undergoing percutaneous endoscopic gastrostomy. Endosc 2004, 36(6):522-526.

6. Harris JA, Benedict FG: A biometric study of human basal metabolism. Proc Natl Acad Sci (USA) 1918, 4(12):370-373.

7. Stacher $G$, Lenglinger J, Bergmann H, Schneider C, Hoffmann M, Wölfl G, Stacher-Janotta G: Gastric emptying: a contributory factor in gastrooesophageal reflux activity?. Gut 2000, 47(5):661-666.

8. Andres JM, Mathias JR, Clench $M H$, Davis RH: Gastric emptying in infants with gastroesophageal reflux: measurement with a technetium-99mlabeled semisolid meal. Dig Dis Sci 1988, 33(4):393-399.

9. Coben RM, Weintraub A, DiMarino AJ Jr, Cohen S: Gastroesophageal reflux during gastrostomy feeding. Gastroenterol 1994, 106(1):13-18.

10. Ayello EA, Thomas DR, Litchford MA: Nutritional aspects of wound healing. Home Healthc Nurse 1999, 17(11):719-729.

11. Pinchcofsky-Devin GD, Kaminski MV Jr: Correlation of pressure sores and nutritional status. J Am Geriatr Soc 1986, 34(6):435-440.

doi:10.1186/1752-1947-4-24

Cite this article as: Nakayama et al:: Prompt improvement of a pressure ulcer by the administration of high viscosity semi-solid nutrition via a nasogastric tube in a man with tuberculosis: a case report. Journal of Medical Case Reports 2010 4:24

\section{Submit your next manuscript to BioMed Central and take full advantage of:}

- Convenient online submission

- Thorough peer review

- No space constraints or color figure charges

- Immediate publication on acceptance

- Inclusion in PubMed, CAS, Scopus and Google Scholar

- Research which is freely available for redistribution

Submit your manuscript at www.biomedcentral.com/submit 